Bol. Acad. peru. leng. 49. 2010 (149-155)

\title{
EL ESTUDIO DE LA LEXICOGRAFÍA TEÓRICA: A PROPÓSITO DE UN NUEVO PROYECTO LEXICOGRÁFICO DEL ESPAÑOL PERUANO Y DE DOS LIBROS DE DIVULGACIÓN
}

\author{
José Carlos Huisa Téllez \\ Universidad de Augsburgo
}

Fecha de recepción:

$04 / 11 / 2009$

Fecha de aceptación:

$02 / 01 / 2010$

En el número 47 del Boletín de la Academia Peruana de la Lengua (enerojunio 2009) se acaba de presentar la Planta del Diccionario de Peruanismos DiPERÚ, como parte del recién iniciado proyecto lexicográfico del español peruano, que la Academia Peruana de la Lengua (APL) ha decidido llevar a cabo bajo la dirección técnica del Profesor Dr. Julio Calvo Pérez. ${ }^{1}$ Este proyecto se une al que ya hace varios años viene desarrollándose en la Universidad de Augsburgo, Alemania, dentro del marco del proyecto Diccionarios Contrastivos del Español de América, dirigido por el Profesor Dr. Reinhold Werner y que cuenta con el apoyo parcial de la Pontificia Universidad Católica del Perú. De esta manera,

\footnotetext{
En septiembre de 2009 se hizo la presentación en sociedad del proyecto, aunque ya el grupo lexicográfico había comenzado su trabajo unos meses atrás. El discurso de incorporación como académico correspondiente del profesor Calvo el 30 de junio de 2007, "Las palabras encantadas: reflexiones sobre un diccionario de peruanismos" puede considerarse como la partida de nacimiento oficial del proyecto.
} 
ahora son dos los diccionarios de peruanismos que se están elaborando simultáneamente, hecho que no podemos dejar de saludar con agrado.

Debido a que estos dos proyectos persiguen objetivos distintos y se basan en principios lexicográficos diferentes, de tal manera que no utilizan métodos en común, una comparación entre ambos carece de sentido. Sin embargo, es de esperar que a lo largo de la elaboración del DiPERÚ, calculada en aproximadamente tres años desde la fecha actual, surjan diversos artículos o notas que desarrollen cuestiones teóricas y prácticas en torno a la redacción misma de la obra, tal como ocurre en el caso de Augsburgo. ${ }^{2}$ Entre las cuestiones teóricas, es necesario determinar en qué medida y de qué manera el diccionario de peruanismos será diferencial y cuál es el conjunto léxico con el cual se coteja el peruano. En relación con ello, es imprescindible explicar la apelación al "patrimonio general del español" (p. 187), noción bastante parecida a aquella de "español general" que, precisamente por ser vaga y por referirse a algo intangible, ha generado grandes problemas en la lexicografía hispanoamericana. En cuanto a aspectos prácticos, no debería dejarse de lado la explicación de cómo la microestructura, que incluye ya mucha información según la planta del proyecto, brindaría información adicional sobre los características peculiares de las unidades léxicas registradas, que constiuirían la razón principal de su registro (p. 187). Además de los mencionados, los temas que deben ser desarrollados más ampliamente, como parte de la redacción concreta del diccionario, son innumerables: someter a un examen objetivo la planta presentada sería por lo demás conveniente.

El propósito de esta nota no es, sin embargo, llevar a cabo tal examen, sino aprovechar la circunstancia de que la labor lexicográfica haya logrado llamar la atención del círculo académico peruano, para reflexionar en torno al estudio mismo de la lexicografía. Naturalmente, la tarea de elaborar un diccionario, sea cual fuere su corte, no se reduce al hecho de recoger palabras a discreción y presentarlas en orden

2 Lo mismo ha ocurrido en el caso del proyecto Diccionario del español de México, a cargo de Luis Fernando Lara. Este proyecto y el de Augsburgo constituyen actualmente la mayor fuente de los estudios metalexicográficos que tratan el español hispanoamericano. 
alfábetico en forma de libro. El verdadero valor de un diccionario descansa en la cantidad, pero sobre todo en la calidad de la información que sobre aquellas palabras ofrece de manera sistemática. La lexicografía práctica, en el sentido de "arte de hacer diccionarios", se encuentra ahora en un estado de desarrollo bastante avanzado, al que no se puede dejar de prestar atención al afrontar este tipo de tareas. Por otro lado, está claro que la formación de un lexicógrafo en pleno siglo XXI no sólo tiene que apoyarse en el trabajo práctico en un taller de redacción, sino también y especialmente en el acceso a la reflexión teórica actual sobre la disciplina. Con esto no nos estamos refiriendo solamente al manejo de una determinada teoría semántica -siempre deudora de una escuela en especial y de factores ajenos a la labor lexicográfica, que a veces hasta pueden desviar al lexicógrafo de sus objetivos concretos- sino tambien al estudio de la metalexicografía o lexicografía teórica, que abarca, además del estudio de problemas relacionados con la elaboración de diccionarios, la crítica de diccionarios, la historiografía, el uso de los diccionarios, así como la tipología de ellos. Si el reproche constante a la lexicografía hispanoamericana ha sido debatirse entre la descripción timorata de su objeto de estudio, por una parte, y el diletantismo, por otra, ${ }^{3}$ no existe mejor hora para comenzar con la profesionalización de la lexicografía, en el caso peruano, que ésta, cuando precisamente están en marcha dos proyectos lexicográficos distintos y cuando las dos universidades de mayor prestigio están de alguna manera involucradas en ellos.

A diferencia de las tradiciones de relativamente larga data en lengua alemana, francesa o inglesa, por mencionar las más importantes, la producción teórica en torno de los temas lexicográficos en lengua española se han inclinado siempre hacia asuntos descriptivos y dialectales, cuando no a acercamientos historiográficos. ${ }^{4}$ Por otro lado, el desarrollo

3 Ver, por ejemplo, el libro Dimensiones de la lexicografia (1990) de Luis Fernando Lara y los artículos "Miseria y esplendor de la lexicografía hispanoamericana" (1984) de Günther Haensch y "Diccionarios diastráticos en Hispanoamérica: entre la descripción científica y el diletantismo" (1994) de Klaus Zimmermann.

$4 \quad$ En la tradición en español, el término metalexicografía se entiende más bien en sentido amplio. La bibliografía publicada por Ahumada en dos tomos (2006 y 2009) puede dar buena cuenta de ello. 
de la disciplina metalexicográfica en lenguas extranjeras se deja sentir lamentablemente con mucha dificultad en el ámbito hispanohablante. Nombres importantes en la actualidad, aunque las contribuciones son de calidad diversa y muchas veces enfocadas sólo a aspectos determinados, son Manuel Alvar Ezquerra, José Álvaro Porto Dapena e Ignacio Ahumada. Gracias al primero de ellos, el aporte francés ha sido tratado en español. Porto Dapena y Ahumada trabajaron, por su parte, en la conclusión del Diccionario de construcción y régimen de Cuervo, experiencia que los obligó a buscar amparo en la teoría. No hay que olvidar a Manuel Seco, en quien conviven en armonía los dos tipos de lexicógrafos: uno preocupado por la elaboración de un diccionario y otro, por la reflexión teórica en torno a ella. ${ }^{5}$ En Hispanoamérica, Luis Fernando Lara, también lexicógrafo en ambos sentidos, ha articulado una compleja reflexión en torno a la lexicografía, basada en un bagaje filosófico extraordinario.

El manual editado por Gredos en 1982 y escrito por cuatro profesores de Augsburgo, si bien lleva un título sugerente, La lexicografía. De la lingüistica teórica a la lexicografía práctica, y es de muy fácil acceso para los lexicógrafos hispanohablantes, ha perdido actualidad y resulta ahora anticuado. De todas maneras, es claro que se trata de un libro fundamental en el ámbito español, por lo menos para iniciarse en el estudio de la disciplina.

Fuera de nuestra lengua, los tres tomos de Wörterbücher. Dictionaries. Dictionnaires. Ein internationales Handbuch zur Lexikographie. An International Encyclopedia of Lexicography. Encyclopédie internationale de lexicographie, editados en Alemania entre 1989 y 1991 por Franz Josef Hausmann, Oskar Reichmann, Herbert Ernst Wiegand y Ladislav Zgusta, constituyen el manual por excelencia de esta disciplina, no sólo porque desarrolla casi absolutamente todos los temas en torno a ella, sino porque la calidad de las contribuciones es de un nivel muy alto. Sin embargo, el acceso de los lexicógrafos hispanohablantes a esta obra es restringido, básicamente por razones lingüísticas, amén de que la producción bibliográfica alemana

5 En no pocas oportunidades, él mismo se ha referido a la distinción en la lexicografía entre "teólogo" y "misionero". 
muy pocas veces tiene repercusión en nuestras latitudes. Lo mismo ocurre con el trabajo de uno de los editores del manual mencionado, Herbert Ernst Wiegand, cuya obra, compuesta por infinidad de artículos, libros y tratados en conjunto, puede considerarse como la literatura esencial de los estudios metalexicográficos.

Ante esta falta de bibliografía básica para acercarse a la lexicografía teórica desarrollada en otras lenguas, especialmente en alemán e inglés, es necesario anunciar y comentar, no sin entusiasmo, dos obras de relativamente reciente publicación. Se trata de dos trabajos que podemos considerar de divulgación y que aparecieron en 2004.

Los diccionarios del español en el siglo XXI de Günther Haensch y Carlos Omeñaca, a la sazón profesores de la Universidad de Augsburgo, se presenta como la segunda edición de Los diccionarios del español en el umbral del siglo XXI de 1997, si bien se trata en esta ocasión de una edición ampliada de manera sustancial. Ambas ediciones han sido editadas por la Universidad de Salamanca. El subtítulo que comparten es por demás transparente: Problemas actuales de la lexicografía - Los distintos tipos de dicionarios; una guía para el usuario - Bibliografía de publicaciones sobre lexicografía. La parte fundamental, alrededor de 250 páginas, consiste en una clasificación tipológica de las obras lexicográficas, que hace especial referencia a aquellas dedicadas al español en general, y en la que se dedica un apartado a las obras que tratan el español de América. Los criterios de clasificación toman en cuenta un gran número de elementos relacionados con la descripción actual de los diccionarios. La presentación somera de la historia, del desarrollo y de no muchas nociones de la lexicografía, aunque bastante breve, ofrece al lector algunas pautas básicas para iniciarse en el estudio de la disciplina. Exactamente lo mismo se debe decir de la presentación de la Crítica de diccionarios, una de las ramas de la lexicografía teórica más útil para el público no científico.

Decir que Dicionários - uma pequena introdução à lexicografia de Herbert Andreas Welker es una obra de divulgación constituye poco menos que un dislate, aunque el mismo autor lo sugiera por momentos. Escrita en portugués, lengua a la que un hispanohablante puede acercarse 
casi sin ningún problema, y publicada en Brasil, esta obra tiene la gran ventaja de haber sido preparada por un profesor alemán, afincado en ese país sudamericano, al que el acceso a la blibiografía en lengua alemana no le resulta dificultoso. La presentación completa y sorprendentemente didáctica, con ejemplos sacados de la tradición lexicográfica brasileña, de elementos complejos de la metalexicografía, especialmente aquellos relacionados con los componentes y la organización del diccionario monolingüe, que constituyen la tercera parte del libro, convierte a éste en una herramienta imprescindible y sin parangón en el estudio de la disciplina en un ámbito cercano al nuestro. Si bien es cierto que la lectura del portugués no ofrece ninguna dificultad, no estaría de más emprender la elaboración de una versión en español, adecuándola a la tradición lexicográfica en nuestro idioma.

La lectura atenta de estos libros contribuiría no solo a la profesionalización de la disciplina en nuestro ámbito, tanto en su aspecto práctico como en el teórico, acercándonos al nivel de desarrollo alcanzado en otros países, sino también contribuiría a evitar caer en ciertos vicios recurrentes, como la discusión de temas ya superados, el uso indistinto de términos operativos ambiguos o poco transparentes, la crítica de diccionarios basada en la búsqueda y denuncia de errores sin importancia del diccionario académico y la falta de objetivos concretos y prácticos al elaborar un diccionario regional, por citar sólo algunos.

Superar el listón, alto ya de por sí, de una formación básica en lexicografía teórica nos dejaría finalmente en condiciones de afrontar tareas lexicográficas necesarias en nuestro entorno, como la elaboración de diccionarios de aprendizaje del quechua o del aimara para hispanohablantes o viceversa, si queremos convertirnos en una sociedad bilingüe funcionalmente hablando, o la elaboración de diccionarios del español para lusohablantes, ahora que el aprendizaje de nuestro idioma es obligatorio en ciertos niveles básicos de la educación en Brasil. Diccionarios escolares, con el objetivo de apoyar la adquisición paulatina del léxico, son también de primera necesidad. En cuanto al español peruano, una formación sólida en lexicografía nos daría las herramientas necesarias para emprender una descripción seria de nuestro léxico, que 
se puede traducir no sólo en simples diccionarios de peruanismos, sino especialmente en diccionarios estrictamente diferencial-contrastivos, por un lado, o generales, por otro; en diccionarios de indigenismos e históricos; y en tesoros lexicográficos. La elaboración de obras de términos técnicos, teniendo en cuenta la inmensa variación existente en el léxico español, constituye a su vez una tarea que hay que iniciar entre los países de habla hispana y que conducirían al acercamiento a una cierta homogenización terminológica.

Todo la anterior es sólo una declaración de intenciones que nos atrevemos a presentar ahora que, al parecer, la disciplina lexicográfica comienza a ganar adeptos rápidamente en el país.

\section{Correspondencia:}

José Carlos Huisa Téllez

Universidad de Augsburgo.

Correo electrónico: josecarlos.huisa@phil.uni-augsburg.de 